\title{
TRÊS QUESTÕES SOBRE FORMAÇÃO DE LEITORES: BIBLIOTECAS ESCOLARES, PRÁTICA DE LEITURA E FRAGMENTAÇÃO.
}

\author{
Milena Ribeiro Martins ${ }^{1}$
}

\begin{abstract}
Resumo: Este texto trata de três aspectos inter-relacionados do ensino de literatura. O primeiro deles diz respeito à necessidade de bibliotecas escolares e à sua centralidade na formação leitora; apresenta algumas políticas públicas de dotação de acervos e a lei que levaria, idealmente, à existência de bibliotecas em todas as escolas brasileiras. O segundo aspecto discutido é a insistência em discursos sobre o hábito e o prazer da leitura, quando a sua prática deveria ser o foco. Prazer e hábito são vistos como eventuais consequências da prática, motivo pelo qual esta última deve ser o alvo. E o terceiro tópico discute a fragmentação do tempo escolar e a predominância de textos curtos no contexto escolar, em detrimento da leitura de gêneros extensos (como romances e biografias), que propiciem continuidade de experiência leitora.
\end{abstract}

Palavras-chave: Formação de leitores. Letramento literário. Biblioteca escolar. Prática de leitura.

\section{Bibliotecas escolares}

Se uma das principais tarefas da escola é formar leitores, para alcançar esse objetivo é imprescindível considerarmos as condições materiais para a prática da leitura escolar: nem incentivo nem estímulo à leitura, mas a sua efetiva prática, aqui concebida como responsabilidade da escola: de todos os professores e gestores, dentro de condições infraestruturais garantidas pelas esferas administrativas (Secretarias Municipais e Estaduais e Ministério da Educação). A despeito de ser óbvia, a explicitação dessa responsabilização é necessária quando tratamos de uma prática essencial, que atravessa a rotina escolar em todas as disciplinas e níveis de ensino, e que, se bem desenvolvida, é essencial para a vida em sociedade, não apenas para aprendizagem na escola.

Para que a formação de leitores tenha efeito, é imprescindível haver livros, para além dos didáticos. Em escolas privadas, é comum que livros para leitura (literária e informativa) sejam parte do material escolar e, como tal, sejam adquiridos no começo do ano letivo pelos pais dos alunos. Esses livros recebiam (e às vezes ainda recebem) o nome de "paradidáticos", adjetivo que deixa a falsa impressão de que eles desempenham uma função paralela ao ensino, e de que ler

\footnotetext{
${ }^{1}$ Professora da UFPR. Doutora em Teoria e História Literária (Unicamp, 2003), com Pós-doutorado em Literatura Brasileira (Usp, 2016). Tem pesquisas nas áreas de História do livro, Modernismo brasileiro, a obra de Monteiro Lobato e Formação de Leitores.
} 
especialmente literatura não é exatamente estudar. Essa é uma concepção equivocada: o letramento literário tem por objetivo desenvolver determinadas habilidades de leitura imprescindíveis para a prática da leitura em sociedade, dentro e fora da escola, mesmo quando se lê aquele tipo de literatura que dá prazer, que promove a evasão e o devaneio. (SOARES, 2004; COSSON, 2009) Em suma, a prática de leitura na escola é parte da formação de bons leitores; e a escola forma leitores para que os estudantes acessem determinados conteúdos, mas também para que se tornem aptos a se apropriarem de forma independente e crítica dos bens da cultura letrada.

Diferentemente de outras sociedades em que bibliotecas estão entre as instituições públicas de promoção e difusão da cultura escrita, no Brasil essas instituições culturais são insuficientes e, quando existem, tendem a ser subutilizadas. Daí decorre a centralidade das bibliotecas escolares como condição para o acesso a variados tipos de livros e textos - não apenas aqueles que, pelas leis do mercado, podem ser adquiridos em livrarias.

A despeito da importância inequívoca dos livros e da biblioteca em ambiente escolar, nem sempre o espaço escolar de leitura está associado com a biblioteca. Muitas vezes, a leitura se reduz a lição de casa: o estudante leva para casa os textos que deve ler para uma data combinada. Dentro da escola, por sua vez, a leitura se realiza em espaços variados: na sala de aula, predominantemente, e em espaços multiuso, de aprendizagem ou de lazer (biblioteca ou sala de leitura, cantinhos, pátio, quadra, jardins, etc.). Essa diversidade nem sempre é sintoma de que a escola possui espaços adequados para leitura, mas sinaliza a identidade da biblioteca como espaço de passagem ou (pior ainda) como depósito inóspito de materiais variados.

Os acervos que constituem as bibliotecas escolares (e o uso que deles se faz) participam de sua identidade e de sua relevância no ambiente escolar. Assim, se a biblioteca tem um bom acervo, ela pode se tornar espaço essencial de aprendizagem, central para a dinâmica escolar, mas isso não acontece quando seu acervo é insuficiente, desinteressante, ultrapassado, de difícil acesso ou, ainda, desconhecido pela comunidade escolar.

Por vários anos, desde pelo menos 1998, estendendo-se ininterruptamente até 2015 , políticas públicas de composição de acervos contribuíram para mudar 
esse cenário. Livros didáticos e livros de literatura foram distribuídos a escolas brasileiras de todos os estados por meio de programas como o PNBE (Programa Nacional da Biblioteca Escolar) e o PNLD (Programa Nacional do Livro Didático). (PAIVA, 2012)

No que diz respeito ao PNBE, trata-se de um rico acervo de obras literárias, que foi selecionado e distribuído anualmente pelo MEC. No intervalo entre 1998 e 2015, o programa passou por mudanças significativas: houve distribuição de livros aos alunos e suas famílias, a professores, houve distribuição de caixas de livros para as bibliotecas (sendo essa a sua forma mais contínua), houve também distribuição de livros adequados a portadores de necessidades especiais e houve, ainda, distribuição de periódicos. O programa se segmentou em uma variedade de subprogramas: Literatura em minha casa, Palavras da Gente, Casa da Leitura, PNBE Temático, PNBE do Professor, PNBE VOLP (Vocabulário Ortográfico da Língua Portuguesa), PNBE Periódicos, PNBE Especial, além de ter se interseccionado com o PNLD, por meio do PNLD-Obras Complementares. Nessas quase duas décadas, o programa se consolidou como uma política contínua de distribuição de livros, sobretudo para composição dos acervos das bibliotecas escolares.

Alguns elementos dessas políticas ainda existem, mas se tornaram intermitentes desde 2015.

Em geral as escolas públicas brasileiras não são dotadas de boas bibliotecas escolares; muitas vezes, o que têm são espaços onde se armazenam livros. Às vezes por criatividade, outras por eufemismo, o espaço destinado a livros recebe nomes variados, além de biblioteca: sala de leitura e cantinho da leitura são os mais comuns. Bibliotecas, propriamente ditas, há poucas. (PAIVA e BERENBLUM, 2009)

Qual a diferença entre tais espaços? Bibliotecas não se reduzem a espaços físicos, mas contam com um profissional capacitado para organizar os livros e (idealmente) para agir como mediador de leitura. Em geral, o que se encontra nas bibliotecas escolares brasileiras são professores de diversas áreas ou funcionários administrativos que ocupam uma função para a qual não foram formados nem capacitados. Podem ter boa-vontade, mas raramente se reconhecem como formadores de leitores. 
Pesquisas feitas no âmbito do projeto "Formação de Leitores: integrando biblioteca e sala de aula" (AUTOR, 2014/2015) e outras pesquisas correlatas, desenvolvidas nos últimos anos em escolas públicas de Curitiba e região metropolitana, não trazem consolo. (MALHADAS, 2014; DURAU, 2016; MARCHEWSKI, 2016; LIMA, 2016; SANTOS, 2016; VALCANOVER, 2018) Indicam que as bibliotecas escolares estão longe de atender às necessidades mais imediatas da escola: quando há bibliotecas, elas abrem nos horários de aulas, mas ficam fechadas nos horários de intervalo; abrem nos dias letivos, mas não em feriados, dias de recuperação, recesso e férias escolares; não estão integradas ao espaço escolar; não são frequentadas pelos professores e funcionários das escolas. Não é raro que o espaço da biblioteca seja ameaçado, reduzido ou tomado de assalto quando a escola precisa abrir mais uma sala de aula; quando isso acontece, os livros vão parar em qualquer espaço: ficam encaixotados em espaços administrativos, nos corredores e, até mesmo, em banheiros. Tais pesquisas não sugerem que a marginalidade da biblioteca estaria, eventualmente, associada a uma suposta centralidade da tecnologia, de salas de computadores ou multimídia. Esses também são espaços e equipamentos insuficientes nas escolas públicas pesquisadas (motivo pelo qual não nos referiremos à leitura de livros em suporte eletrônico).

$\mathrm{Na}$ falta de condições materiais mínimas para alcançar o objetivo educacional de formar leitores, de desenvolver em leitores alfabetizados habilidades de leitura que os tornem leitores autônomos e críticos, professores contam quase sempre consigo mesmos. Esse sentimento de que trabalham sozinhos, sem o devido suporte institucional, a despeito do enquadramento de um serviço público, faz crescer e ganhar corpo a ideia de que o magistério é a expressão de uma missão, uma vocação, uma atividade feita por amor.

Sem recusar a importância e o efeito inspirador de ações vocacionadas, de missionários e voluntários, propõe-se aqui a desvinculação linguística entre a aura religiosa e a ação educacional. Quando se compreende (ainda que simbolicamente) a atuação de profissionais da educação como resposta a um chamado divino, tais profissionais se converte em seres especiais, alimentados por uma luz divina que os impeliria a agir mesmo a despeito da falta de condições infraestruturais, mesmo com o sacrifício de sua humanidade. 
A religiosidade ocupa outras esferas da vida dos sujeitos. Na vida profissional, sua formação - da qual faz parte a ética profissional - deveria ser posta em primeiro plano.

A metáfora religiosa alimenta a ideia de que o professor que não se entrega "de corpo e alma" à sua suposta vocação comete um ato vil, um pecado, ou no limite uma blasfêmia. Por esses motivos, dentre outros, a metáfora religiosa não deveria se impor sobre ações educacionais. Em lugar dela, propõe-se aqui o reconhecimento de que educadores prestam serviço à sociedade, assumem um compromisso ético com o mundo em que vivem. Dedicação, envolvimento afetivo e criatividade - característicos de muitos profissionais da educação - não estão desvinculados desse compromisso ético.

Professores agem por meio de estruturas que lhes permitem desenvolver suas funções. Ou que não lhes permitem. Para formar leitores, é imprescindível que haja textos (em variados suportes, de variados gêneros), algum silêncio e luz; é preciso que haja um diploma antes de começar e salário digno para que se possa continuar. Esse é o mínimo sem o qual não superaremos os discursos de incentivo e estímulo à leitura. Essas palavras tão usadas - incentivo e estímulo - são também ligadas à imaterialidade do ato de ler, porque tratam de ações que habitam a antessala da leitura, fazem referência à eterna preparação de um clima ou de um espírito propício para o ato de ler.

Sem bibliotecas, o acesso a livros é limitado à compra. Quem não compra fica impedido se entrar nessa festa: é barrado no baile. A biblioteca não substitui a compra de livros, ela não serve apenas a quem não pode comprar livros, mas serve para que a prática de leitura esteja dissociada do consumo. A biblioteca é como uma grande arca de um tesouro legada a uma sociedade por seus antepassados, de que todos são herdeiros (segundo metáfora de Ana Maria Machado, 2002). E, por sermos todos herdeiros, temos direito de conhecer e usufruir desse tesouro, que são os conhecimentos, as reflexões e as histórias acumuladas e preservadas por meio da escrita.

O acesso aos livros depende não apenas da existência das bibliotecas, mas também de seu uso, da compreensão dos textos que só é alcançada pela formação leitora: abrir livros, lê-los, frequentar bibliotecas, entender minimamente sua organização, tirar livros dos seus lugares, folheá-los, escolher alguns dentre 
outros, emitir opiniões livremente sobre os livros lidos, ouvir opiniões, produzir novos livros, colaborando com a dinamização desse acervo - tudo isso é parte constitutiva da formação leitora. Compartilhar impressões é fundamental para formar leitores, porque é em sociedade que os sentidos são construídos. (KOCH E ELIAS, 2008)

Ler implica troca de sentidos não só entre o escritor e o leitor, mas também com a sociedade onde ambos estão localizados, pois os sentidos são resultado de compartilhamento de visões do mundo entre os homens no tempo e no espaço. [...] O bom leitor, portanto, é aquele que agencia com os textos os sentidos do mundo, compreendendo que a leitura é um concerto de muitas vozes e nunca um monólogo." (COSSON, 2009, p. 2627)

Há na Constituição brasileira a possibilidade e a promessa de superação dessa ausência de bibliotecas escolares. A lei 12.244, promulgada em 2010, prevê a existência de bibliotecas escolares em todas as instituições de ensino brasileiras, públicas e privadas, de todos os níveis:

\section{LEI № 12.244 DE 24 DE MAIO DE 2010.}

Dispõe sobre a universalização das bibliotecas nas instituições de ensino do País.

O PRESIDENTE DA REPÚBLICA Faço saber que o Congresso Nacional decreta e eu sanciono a seguinte Lei:

Art. 1‥ As instituições de ensino públicas e privadas de todos os sistemas de ensino do País contarão com bibliotecas, nos termos desta Lei.

Art. 20 Para os fins desta Lei, considera-se biblioteca escolar a coleção de livros, materiais videográficos e documentos registrados em qualquer suporte destinados a consulta, pesquisa, estudo ou leitura.

Parágrafo único. Será obrigatório um acervo de livros na biblioteca de, no mínimo, um título para cada aluno matriculado, cabendo ao respectivo sistema de ensino determinar a ampliação deste acervo conforme sua realidade, bem como divulgar orientações de guarda, preservação, organização e funcionamento das bibliotecas escolares.

Art. 3o Os sistemas de ensino do País deverão desenvolver esforços progressivos para que a universalização das bibliotecas escolares, nos termos previstos nesta Lei, seja efetivada num prazo máximo de dez anos, respeitada a profissão de Bibliotecário, disciplinada pelas Leis nos 4.084, de 30 de junho de 1962, e 9.674, de 25 de junho de 1998. 2010).

Art. 40 Esta Lei entra em vigor na data de sua publicação. (BRASIL,

Apesar de essa lei estabelecer prazo para a universalização das bibliotecas escolares - que vencerá em breve -, ela não é amplamente conhecida, tampouco 
há noticias de que seu cumprimento se efetivará no prazo previsto. Em lugar de caminharmos para alcançar tal universalização, temos caminhado no sentido contrário, por meio da extinção ou do estrangulamento de políticas públicas de distribuição de livros para as bibliotecas existentes.

\section{Prática de leitura}

Muito já se falou e escreveu sobre o prazer da leitura e sobre o incentivo à leitura. A despeito da importância dessas bandeiras, as ações formativas precisam ser concebidas para a efetiva prática da leitura. Trata-se de mais uma obviedade, um objetivo muito buscado, mas ainda não alcançado. É incontornável que a escola seja espaço de leitura: nas salas de aula, na biblioteca, no pátio e na sala dos professores. O prazer da leitura pode ser alcançado por quem lê, se esse sujeito-leitor compreende minimamente o que lê. O prazer pode ser um efeito da leitura, da compreensão e fruição dos textos; não é ponto de partida, mas pode ser parte do processo de leitura.

A inquietação em torno das muitas funções dos professores que formam leitores não é exclusivamente nossa. A antropóloga Michèle Petit assim descreve essas funções referindo-se à situação do ensino na França:

\footnotetext{
É preciso acrescentar ainda que dos professores é exigido algo impossível, um verdadeiro quebra-cabeça chinês. Espera-se deles que ensinem as crianças a "dominar a língua", como se diz no jargão oficial. Que as convidem a partilhar desse suposto "patrimônio comum". Que as ensinem a decifrar textos, a analisar e a ler com certo distanciamento. E, ao mesmo tempo, que as iniciem no "prazer de ler". Tudo isso é objeto de muitos debates, de muitos questionamentos entre esses profissionais. (PETIT, 2008, p. 158)
}

Da mesma forma, aqui, a insistência nos discursos a respeito do prazer e do hábito de ler parece às vezes se substituir à sua efetiva prática. Algumas perguntas que emergem em eventos sobre leitura, em feiras de livros, em conversas com alunos de licenciaturas, candidatos a professores, são: "É possível formar o leitor que não tem hábito de ler? Se a família não lê, como o professor vai conseguir formar esse leitor? E se o aluno sequer tem livros em casa?" 
Se o leitor sem hábito de ler chega à escola, ele tem tanto direito quanto todos os outros (e talvez ainda mais necessidade que os demais) de desenvolver suas habilidades leitoras. É tarefa da escola, portanto, dotá-lo da habilidade de ler. O hábito de ler não se desenvolve sem a prática rotineira da leitura. Em outras palavras, o hábito da leitura é, também, consequência da prática.

Uma última inquietação, enunciada sistematicamente por professores de língua portuguesa, trata do receio de gastar tempo demais lendo, já que o currículo da disciplina é extenso, e o tempo é curto. Quando consideram que ensinar língua é dedicar-se a ortografia, crase, à tipologia das orações subordinadas, aos mais variados gêneros textuais, dentre outros inúmeros assuntos urgentes, professores de língua portuguesa sentem não ter tempo para dedicar à leitura.

Esse, porém, é um falso dilema: em torno da leitura e a partir da leitura (associada à escrita e oralidade) constroem-se os saberes sobre a linguagem e sobre a cultura, desde a ortografia e a colocação pronominal, até a coerência e a consciência sobre gêneros textuais e literários.

\section{Sobre fragmentação e continuidade}

Outro aparente entrave para a formação de leitores na escola é a fragmentação do tempo escolar: no ensino fundamental e médio, o tempo de permanência do estudante na escola é fragmentado em pequenos blocos de 45 ou 50 minutos. Também o livro didático é fragmentado em unidades e capítulos. Os textos dos livros didáticos, por sua vez, são fragmentos de romances, ou são poemas, ou ainda fragmentos de poemas.

Talvez em função dessa divisão do tempo, mas também em função de alguns hábitos arraigados na cultura escolar, há uma certa preferência por textos curtos na escola, textos que permitem que uma atividade se inicie e se encerre numa mesma aula. É bem-intencionado aquele professor que escolhe um conto para ler em aula, ou uma crônica, ou um poema, porque essas pequenas unidades Ihe permitem organizar seu tempo pedagógico. Com um texto curto, o professor se organiza de forma a ter condições de concluir uma atividade no tempo de uma aula. No livro didático, o professor encontra um estímulo para essa prática: lá estão textos curtos, que cabem no espaço das unidades em que o livro se divide. $O$ 
mesmo se dá com apostilas. Os textos começam e terminam no espaço de uma unidade. E, para coroar essa fragmentação de tempo, de unidades de aprendizagem e de textos, também no Enem só há textos curtos, que começam e acabam numa questão.

Assim, a escola, os materiais didáticos e também o exame nacional do ensino médio alimentam, geração após geração, a ideia de que texto bom é texto curto, que se lê sem demora; daí decorreria a compreensão de que texto comprido seria ruim em essência, inadequado à fragmentação do tempo escolar.

Trata-se de um falso pressuposto, embora sua associação com outros gêneros textuais da contemporaneidade (textos publicitários, manchetes de jornais, microconto, tuíter, memes, etc.) pareça fazer da brevidade um elemento essencial do nosso tempo. Algumas vezes é assim, mas não precisa ser sempre assim.

Se textos curtos habitam nosso cotidiano, a extensão e a continuidade também a constituem. Um exemplo disso são as séries de ficção, seja em livros, seja em filmes, de que se podem citar dezenas de exemplos, dentre os quais a trilogia de J. R. R. Tolkien, $O$ Senhor dos Anéis, ou uma coleção mais antiga, $O$ Tempo e o Vento, de Erico Verissimo, ou ainda Harry Potter, de J. K. Rowling, cujos livros de centenas de páginas, em volumes que se sucedem, desafiam a crença de que jovens não gostam de textos longos. Exemplos mais atuais de coleções juvenis significativamente extensas são Terra de histórias, de Chris Colfer, e Diário de Pilar, de Flávia Lins e Silva. E abundam exemplos de séries clássicas, como a coleção do Sítio do Picapau Amarelo, de Monteiro Lobato, ou O mágico de Oz e suas sequências, de Frank L. Baum. São exemplos cujo sucesso de mercado indicam que crianças e jovens leitores do passado e do presente também aspiram por extensão e por continuidade.

Embora se possa sustentar a ideia de que o tempo é fragmentado e que isso define a cultura contemporânea, não parece possível sustentar o argumento de que o professor e o autor de livros didáticos escolhem textos curtos para satisfazer a uma demanda advinda do desejo dos jovens leitores. E se, ainda assim, certos grupos de leitores preferirem textos curtos, a experiência da leitura de textos extensos, de histórias que têm continuidade, precisa ser alimentada ao longo da formação leitora. A razão é elementar: na formação leitora, é imprescindível a 
experiência de leitura de uma variedade de gêneros, dentre os quais estão gêneros extensos, como romances, biografias e livros científicos.

Se o texto breve suscita algumas formas de satisfação - porque encerrar ciclos e unidades pode trazer em si algo de positivo - também é importante (e pode ser prazerosa e formadora) a experiência de vivenciar temas e histórias que têm continuidade, às quais o leitor pode voltar. $\mathrm{O}$ reencontro com personagens, a convivência extensa e intensiva com um determinado ambiente narrativo, com um estilo, trazem ao cotidiano leitor a durabilidade que também perpassa situações de vida.

Nesse sentido, a noção de continuidade parece ser um valor positivo na formação do leitor, seja na produção de sentido, seja no aprofundamento da compreensão do que se lê. Isso é bastante claro quando se trata da leitura de livros em série, como os citados, mas também parece ser verdade quanto à leitura de textos curtos e aparentemente fragmentados: afinal, um poema, um conto, uma crônica são parte integrante de um núcleo maior, seja de um livro de poemas, seja de um jornal onde a crônica foi originalmente publicada, e sua significação se amplia e se adensa na relação com os outros textos que compõem essa unidade.

Insistir na continuidade das histórias, na inserção de um texto curto no universo maior de que ele faz parte, e também insistir na leitura de histórias longas são formas de buscar a profundidade da apreensão dos sentidos. É salutar a compreensão mais profunda dos fenômenos, dos fatos sociais, assim como dos textos. Para uma compreensão mais profunda dos textos que fazem parte - ou deveriam fazer parte - do cotidiano escolar, os blocos de 45 minutos de uma aula precisam ser planejados em função de uma unidade maior. Se isso é feito regularmente com relação ao currículo, pode também ser feito no que diz respeito à leitura, que, iniciando-se num dia, pode ter continuidade nos dias subsequentes.

Os estudantes de hoje vivem num mundo ao mesmo tempo fragmentado e em rede: pequenos pedaços de informação, textos curtos, conexões inúmeras, tudo se conectando, idealmente, em redes de relações que permitem a construção de sentido.

Estabelecer relações entre as partes de um texto extenso, como um romance, por exemplo, é uma habilidade pouco ou nada exercitada na leitura de textos menores, como uma manchete ou uma notícia de jornal, ou um quadrinho, 
ou uma letra de música. A ênfase na leitura exclusiva de textos curtos, em contexto escolar, negligencia o desenvolvimento de habilidades ligadas à continuidade, à permanência, e que são essenciais não apenas para a vida escolar, mas para a vida em sociedade. Essa negligência tem sido aceita (e apoiada) pelo Enem, pelos livros didáticos e, algumas vezes, pelas escolas. Ler romances (e outros gêneros extensos), ler contos em livros de contos, ler livros inteiros de poemas são formas de resistir à fragmentação, de insistir na continuidade e no aprofundamento continuidade dos fatos, das ideias, das experiências; aprofundamento da compreensão, da percepção, das relações.

\title{
THREE QUESTIONS ABOUT READER TRAINING: SCHOOL LIBRARIES, READING PRACTICE AND FRAGMENTATION.
}

\begin{abstract}
This essay deals with three interrelated aspects of teaching literature. The first one concerns the need for school libraries and their centrality in reading training; it also presents some public policies for building library collections, and a specific law that ideally determines the existence of libraries in all Brazilian schools. The second aspect discussed is the insistence on discourses about the habit and the pleasure of reading, when its practice should be the focus. Pleasure and habit are seen as possible consequences of practice, which is why practice should be the target. The third and last topic discusses the fragmentation of school time and the predominance of short texts in the school context, to the detriment of reading long genre (such as novels and biographies) that provide the continuity of reading experience.
\end{abstract}

Keywords: Reader training. Literary literacy. School library. Reading practice.

\section{Referências bibliográficas}

BRASIL. Lei n. 12.244 (2010). Dispõe sobre a universalização das bibliotecas nas instituições de ensino do País. Diário Oficial da União, 25/05/2010, p. 3. Disponível em <https://www.planalto.gov.br/ccivil_03/_ato2007-2010/2010/lei//12244.htm>. Último acesso em 24.10.2019.

COSSON, Rildo. Letramento literário: teoria e prática. São Paulo: Contexto, 2009.

DURAU, Jucimari Aparecida Merchiori. A prática de leitura e escrita no ensino fundamental com contos de mistério, Cadernos PDE, Produções didáticospedagógicas, Volume II. Disponível em <http://www.diaadiaeducacao.pr.gov.br/portals/cadernospde/pdebusca/producoes pde/2016/2016_pdp_port_ufpr_jucimariaparecidamerchiori.pdf> Último acesso em 24/10/2019.

$\mathrm{KOCH}$, Ingedore; ELIAS, Vanda. Ler e compreender: os sentidos do texto. 2.ed. São Paulo: Contexto, 2008. 
LIMA, Charlene da Silva Andrade de. Farol do Saber: Limites e possibilidades na formação de leitores de uma biblioteca escolar em Curitiba. Dissertação de Mestrado, Programa de Pós-Graduação em Educação, Universidade Federal do Paraná, 2016.

MACHADO, Ana Maria. Como e por que ler os clássicos universais desde cedo. Rio de Janeiro: Objetiva, 2002.

MALHADAS, Paula Augusta Assumpção. Programa Nacional Biblioteca da Escola (PNBE 2011): um estudo de caso. Monografia de conclusão de curso. [mimeo] UFPR, 2014.

MARCHEWSKI, Márcia Eliane Kochinski. A narrativa de aventura e a prática de leitura e escrita no ensino fundamental, Cadernos PDE, Produções didáticospedagógicas, Volume II. Disponível em

<http://www.diaadiaeducacao.pr.gov.br/portals/cadernospde/pdebusca/producoes _pde/2016/2016_pdp_port_ufpr_marciaelianekochinski.pdf> Último acesso em 24/10/2019.

MARTINS, Milena Ribeiro (coord.). Formação de leitores: integrando biblioteca e sala de aula. Projeto Pibid Capes/UFPR. [mimeo] 2014/2015.

PAIVA, Aparecida (org). Literatura fora da caixa: O PNBE na escola - distribuição, circulação e leitura. São Paulo: Unesp, 2012.

PAIVA, Jane; BERENBLUM, Andréa. Programa Nacional Biblioteca da Escola (PNBE) - uma avaliação diagnóstica, Pro-Posições, Campinas, v. 20, n. 1 (58), p. 173-188, jan./abr. 2009.

PETIT, Michelle. Os jovens e a leitura: uma nova perspectiva. Tradução de Celina Olga de Souza. São Paulo: Ed. 34, 2008.

PETIT, Michelle. A arte de ler ou como resistir à adversidade. Tradução de Arthur Bueno e Camila Boldrini. São Paulo: Ed. 34, 2009.

SANTOS, Angelita Maria dos. Letramento literário: uma proposta transdisciplinar. Monografia de conclusão de curso. [mimeo] UFPR, 2016.

SOARES, Magda. Letramento: um tema em três gêneros. Belo Horizonte: Autêntica, 2004.

VALCANOVER, Camila Augusta. Trabalha e teima e lima e sofre e sua: Letramento Literário no Ensino Fundamental II. Dissertação de Mestrado, Programa de PósGraduação em Educação, Universidade Federal do Paraná, 2018. 